\title{
Field efficacy of some biorationals against the two spotted spider mite Tetranychus urticae Koch (Acari: Tetranychidae)
}

\author{
Kanika Tehri* and Rachna Gulati \\ Department of Zoology, CCS Haryana Agricultural University, Hisar (125004), INDIA \\ *Corresponding author. E- mail: knkzoology@gmail.com \\ Received: February 8, 2014; Revised received: February 25, 2014; Accepted:March 10, 2014
}

\begin{abstract}
Field trials were conducted to evaluate the acaricidal potential of entomopathogenic fungus, Beauveria bassiana and aqueous extracts of Withania somnifera and Glyccirrhyza glabra against the mobile stages of Tetranychus urticae Koch on cucumber. The treatments responded in a concentration dependent manner. Highest reduction in $T$. urticae population was achieved with Omite $(0.05 \%)$ followed by Nimbecidine $(5 \mathrm{ml} / \mathrm{l})$, B. bassiana $\left(10^{10}\right.$ spores $\left.\mathrm{ml}^{-1}\right)$, W. somnifera $(7.5 \%)$, B. bassiana $\left(10^{8}\right.$ spores $\left.\mathrm{ml}^{-1}\right)$, G. Glabra $(7.5 \%)$, G. Glabra $(5 \%)$, G. Glabra $(2.5 \%), W$. somnifera (5\%) and W. somnifera (2.5\%). Higher yield was recorded in all the treatments as compared to control. In terms of percent increase in yield, Omite caused highest increase $(23.65 \%$ over control) followed by Nimbecidine, B. bassiana $\left(10^{10}\right.$ spores/ ml), W. somnifera (7.5\%), B. bassiana $\left(10^{8}\right.$ spores/ ml), G. Glabra (7.5\%), W. somnifera (5\%), G. Glabra (5\%), G. Glabra (2.5\%), and W. somnifera (2.5\%) showing 13.97, 11.82, 10.75, 8.67, $8.67,8.6,6.76,6.48$ and 6.45 percent increase over control, respectively. These data suggest that the tested biorationals at higher concentrations have the potential to be employed in pest management programs designed for T. urticae control.
\end{abstract}

Keywords: Beauveria bassiana, Cucumber, Glyccirrhyza glabra, Tetranychus urticae, Withania somnifera

\section{INTRODUCTION}

The two-spotted spider mite, Tetranychus urticae Koch, has now evolved as a major agricultural pest feeding on more than 900 plants including field crops, horticultural crops, green house vegetables and ornamental plants; often causing 50 to 100 percent yield loss (Kumar et al., 2010; Clotuche et al., 2011). Computer modelling suggests that with intensifying global warming, the detrimental effects of spider mites in agriculture will markedly increase due to accelerated development at high temperatures (Migeon, 2009). Traditionally, two-spotted spider mite has been controlled using synthetic chemical acaricides with a level of residuality and permanence that constitutes a barrier to the commercialization of agricultural products and causes detrimental effects to environment and human health. Unfortunately, $T$. urticae is one of the most striking examples of polyphagy among herbivores with an unmatched ability to develop resistance to pesticides. Many aspects of the biology of this mite; including rapid development, high fecundity and haplo-diploid sex determination; seem to facilitate rapid evolution of pesticide resistance (Van Leeuwen et al., 2010). Currently, great efforts are directed towards reduction in the use of traditional pesticides and increase in the use of Integrated Pest Management (IPM) strategies. Pesticides formulated with herbal extracts are thus in practice as a safer alternative and have become part of leading research all over the world (Clemente et al., 2003). Studies have demonstrated that chemicals derived from plants are safer, specific in action, biodegradable and potentially suitable for use in integrated pest management programmes. More than 2000 plant species including medicinal plants and spices are known to have insecticidal and miticidal properties (García et al., 2004). They constitute a rich source of bioactive compounds which might act deadly on the pests' physiological system and kill them (Daoubi et al., 2005). Glycyrrhiza glabra (Liquorice) (Family: Fabaceae) and Withania somnifera (Ashwagandha) (Family: Solanaceae) are widely used medicinal plants in Indian traditional medical practice and their extracts have also been tested for insecticidal action against insects of agricultural importance (Bastos et al., 2009). Members of the mitosporic (Hyphomycetes) entomopathogens are promising microbial control agents against acari as these fungi invade the host by growing through the external cuticle (Chandler et al., 2000). They can be produced in mass using low input technology, easily formulated as myco-pesticides suitable for spraying using conventional chemical spraying equipment, are less harmful to non-target arthropods and mammals and are, therefore, ideal for IPM program strategies. Among the fungi used as biological control agents (BCAs), Beauveria bassiana is a classical entomopathogen and has been extensively 
used for control of many important pests of various crops around the world (Varela and Morales, 1996). Keeping in view the above facts and need for search of effective biointensive control measures, it was decided to evaluate the acaricidal activity of leaf extract of $W$. somnifera, stem extract of G. glabra and B. bassiana against $T$. urticae on cucumber, a major vegetable crop and potential host for the pest.

\section{MATERIALS AND METHODS}

Preparation of botanical extracts: Glycyrrhiza glabra stems and Withania somnifera leaves were collected from Medicinal Plants Farm Area and University Campus, respectively. The stems $(1 \mathrm{~kg})$ and leaves $(1 \mathrm{~kg})$ were coarsely ground and soaked in one litre of distilled water for 48 hours with intermittent shaking at room temperature. After 48 hours, the solutions were filtered through muslin cloth and collected in separate glass bottles. Considering both the aqueous stock solutions as 100 per cent pure, three different concentrations $(2.5,5$ and $7.5 \%$ each) were prepared using distilled water by volume to volume dilution method.

Beauveria bassiana cultures: The culture of $B$. bassiana (strain- Hyderabad) was raised on Potato Dextrose Agar media in $250 \mathrm{ml}$ conical flasks for experimental purpose which is a standard procedure (Vimala Devi, 2003). Regular passaging and maintenance was done for further multiplication at $27 \pm 2^{\circ} \mathrm{C},>90 \% \mathrm{RH}$ and 16: 8 (Light: Dark) photoperiod. Pure mother cultures in slants were stored under refrigerated conditions till further use.

Preparation of $\boldsymbol{B}$. bassiana suspension: Aqueous conidial suspensions were made from conidia harvested from the slants prepared in conical flasks after 14 days of inoculation. Conidial spores were harvested by scrapping the surface of sporulating cultures and suspended in $100 \mathrm{ml}$ distilled water containing Tween $80(0.02 \%)$ which was used as surfactant to disperse the conidia. After the conidia came into the solution completely, it was filtered through a double layered muslin cloth. A suspension of $10^{10}$ conidia $\mathrm{ml}^{-1}$ concentration was prepared using haemocytometer counts. Lower conidial concentration $\left(10^{8}\right.$ conidia $\left.\mathrm{ml}^{-1}\right)$ was obtained through serial dilution. Freshly prepared conidial suspensions were used for field evaluation.

Field efficacy: Field trials were conducted at Research Farm, Department of Entomology, CCS Haryana Agricultural University, Hisar to evaluate the efficacy of the above mentioned biorationals against mixed population of mites during 2012. It was measured in terms of the population build up of the pest as affected by changes in the concentration of formulation and duration of exposure. For the present experiment, natural Tetranychus urticae infestation was used. Botanicals and B. bassiana treatments were compared with Nimbecidine (5 ml/ 1 water) and Omite (57 EC @
$0.05 \%$ ) treatments, both considered as standard check. The experimental units comprised three plots each measuring $10 \mathrm{~m} \times 40 \mathrm{~m}$. The cucumber plants were grown on ridges following standard agronomic practices. The plants were irrigated as and when needed. A randomized block design with three replicates was used for experimentation. Four rounds of foliar applications were given; first at the appearance of first chlorotic patch and three subsequent sprays at an interval of 12 days. During application of biorational/ acaricide, the whole plant was thoroughly covered by spray fluid and care was taken to maintain the distance around $25 \mathrm{~cm}$ between the nozzle and plant parts. To judge the potential of particular treatment, ten plants in each replicate of a treatment were selected at random. Observations on the number of $T$. urticae population (mobile stages) per sq. $\mathrm{cm}$ leaf were recorded using hand lens from both upper and lower surface of two leaves from each category (tender, grown up and older) per plant. Apart from pre-treatment count, the post treatment counts (live mites) were recorded after 2, 4, 6, 8, 10 and 12 days of spray. It was easy to distinguish live mites from dead individuals by observing their movement. The live mites were mobile whereas immobile mites failing to respond with leg movements after being tightly nudged with a fine bird feather pick were considered dead.

For assessing the effectiveness of the treatments, mean numbers of $T$. urticae were pooled and analyzed statistically. The percent reduction in mite count as compared to pre- treatment count was calculated by the formula:

Percent Reduction $=($ Pre- treatment count - Average number of live mites after treatment) / Pre- treatment count $\times 100$

The effect of $T$. urticae infestation on the yield of cucumber fruits from treated and untreated plots was recorded to see the effectiveness of treatments against T. urticae infestation. The difference in the fruit yields of cucumber was calculated and the per cent yield gain was worked out by following formula:

Increase in crop yield $=($ Mean yield of untreated crop - Mean yield of treated crop) / Mean yield of untreated crop $\times 100$

Statistical analysis: The statistical significance of data was assessed by Two factorial analysis of variance (ANOVA). Critical difference (CD) was calculated between the treatments under RBD using software 'OPSTAT' to know the efficacy of different treatments in reducing $T$. urticae population in cucumber plants. Means were then compared using Duncan's multiple range test (at $\mathrm{p}=0.05)$.

\section{RESULTS}

The results on the field efficacy of various treatments against $T$. urticae have been presented in Tables 1 and 2. Among the treatments, the recommended acaricide, 
Table 1. Field efficacy of entomopathogenic fungus and botanicals against T. urticae on cucumber during 2012.

\begin{tabular}{|c|c|c|c|c|c|c|c|}
\hline \multirow[b]{2}{*}{ Treatment } & \multicolumn{5}{|c|}{ Average number of mites/ sq. $\mathrm{cm}$ leaf } & \multirow[b]{2}{*}{ Mean } & \multirow[b]{2}{*}{$\begin{array}{c}\text { Reduction } \\
\text { after } \\
\text { treatment }(\%)\end{array}$} \\
\hline & $\begin{array}{l}\text { Pre treatment } \\
\text { count }\end{array}$ & $\begin{array}{c}\text { After } \\
\text { I } \\
\text { spray }\end{array}$ & $\begin{array}{l}\text { After } \\
\text { II } \\
\text { spray }\end{array}$ & $\begin{array}{l}\text { After } \\
\text { III } \\
\text { spray }\end{array}$ & $\begin{array}{l}\text { After } \\
\text { IV } \\
\text { Spray }\end{array}$ & & \\
\hline $\begin{array}{l}\text { B. bassiana } \\
\left(10^{8} \text { conidia } \mathrm{ml}^{-1}\right)\end{array}$ & 3.56 & 1.91 & 1.53 & 1.32 & 1.16 & 1.48 & 58.42 \\
\hline $\begin{array}{l}\text { B. bassiana } \\
\left(10^{10} \text { conidia } \mathrm{ml}^{-1}\right)\end{array}$ & 3.54 & 1.52 & 1.21 & 1.05 & 0.78 & 1.14 & 67.77 \\
\hline $\begin{array}{l}\text { W. somnifera } \\
(2.5 \%)\end{array}$ & 2.52 & 2.27 & 2.63 & 3.09 & 4.69 & 3.17 & -25.79 \\
\hline $\begin{array}{l}\text { W. somnifera } \\
(5 \%)\end{array}$ & 3.14 & 2.16 & 2.19 & 3.34 & 3.79 & 2.87 & 8.59 \\
\hline $\begin{array}{l}\text { W. somnifera } \\
(7.5 \%)\end{array}$ & 2.26 & 1.36 & 1.16 & 1.24 & 1.44 & 1.30 & 42.47 \\
\hline $\begin{array}{l}\text { G. glabra } \\
(2.5 \%)\end{array}$ & 1.66 & 1.86 & 2.69 & 3.07 & 3.29 & 2.73 & -64.45 \\
\hline $\begin{array}{l}\text { G. glabra } \\
(5 \%)\end{array}$ & 1.86 & 1.39 & 1.79 & 2.24 & 2.32 & 1.94 & -4.30 \\
\hline $\begin{array}{l}\text { G. glabra } \\
(7.5 \%)\end{array}$ & 2.02 & 1.45 & 1.51 & 1.85 & 2.18 & 1.75 & 13.36 \\
\hline $\begin{array}{l}\text { Nimbecidine } \\
\text { (5 } \mathrm{ml} / 1 \text { water })\end{array}$ & 2.90 & 1.32 & 1.05 & 0.74 & 0.72 & 0.96 & 66.89 \\
\hline $\begin{array}{l}\text { Omite } \\
(0.05 \%)\end{array}$ & 2.86 & 0.70 & 0.36 & 0.18 & 0.12 & 0.36 & 87.41 \\
\hline $\begin{array}{l}\text { Control } \\
\text { (Water spray) }\end{array}$ & 2.49 & 2.01 & 3.44 & 5.16 & 6.78 & 4.35 & \\
\hline Control (untreated) & 1.85 & 2.57 & 5.09 & 6.91 & 9.38 & 5.98 & \\
\hline
\end{tabular}

Percent reduction in mite count calculated over pre- treatment count.

Omite caused highest reduction $(87.41 \%)$ in mite count. Subjected to four sprays of Nimbecidine, the number of mites fell from a pre treatment count of 2.90 mites/ sq. cm leaf to 0.96 mites/ sq. cm leaf, showing a reduction of 66.89 percent. Similarly, spraying with $B$. bassiana at $10^{10}$ conidia $\mathrm{ml}^{-1}$ and $10^{8}$ conidia $\mathrm{ml}^{-1}$, a percent reduction of 67.77 and 58.42 was witnessed. At the end of experiment, both the treatments led to a decrease in mite population from pre treatment count of 3.54 and 3.56 mites/ sq. cm leaf to 1.14 and 1.48 mites/ sq. cm leaf, respectively. W. somnifera leaf extract tested at 2.5 percent was not effective and resurgence in $T$. urticae population led to increase in mite population from pre treatment count of 2.52 mites/ sq. cm leaf to post treatment count of 3.17 mites/ sq. cm. The same extract tested at 5 and 7.5 percent reduced the mite population from pre treatment counts of 3.14 and 2.26 mites/ sq. cm leaf to post treatment counts of 2.87 and 1.30 mites/ sq. cm leaf, depicting 8.59 and 42.47 percent reduction. Glycyrrhiza stem extract was not effective against $T$. urticae. Among the three concentrations tested, only the highest concentration $(7.5 \%)$ caused 13.36 percent reduction at the end of experiment.

The effects of B. bassiana, W. somnifera and G. glabra doses were compared with standard acaricide, Omite $(0.05 \%)$ and Nimbecidine to see their effectiveness in terms of recovery of mite number in each treatment (Table 2). The results clearly revealed significant differences in number of mites recorded in various treatments with control $(\mathrm{CD}=1.08 ; \mathrm{p}=0.05)$. The treatments differed in their acaricidal action against $T$. urticae over control although it ranged from 50.00 to 98.72 percent. Among the treatments, Omite was most potent in causing 98.72 percent reduction in $T$. urticae number over control. This was closely followed by Nimbecidine $(92.32 \%)$ and $B$. bassiana at $10^{10}$ conidia $\mathrm{ml}^{-1}(91.68 \%)$. Spray of Omite, Nimbecidine, $B$. bassiana $\left(10^{10}\right.$ conidia $\left.\mathrm{ml}^{-1}\right)$ significantly lowered the $T$. urticae population as compared to control $(\mathrm{CD}=1.08$; $\mathrm{p}=0.05)$. These treatments were statistically comparable with each other in terms of number of mites recovered after spray. $B$. bassiana at $10^{8}$ conidia $\mathrm{ml}^{-1}$ caused 87.63 percent reduction in mixed 
Table 2. Comparative evaluation of entomopathogenic fungus and botanicals against $T$. urticae on cucumber under field conditions during 2012.

\begin{tabular}{|c|c|c|c|c|}
\hline Treatment & Dose & No. of mites/sq.cm leaf & $\begin{array}{c}\text { Yield } \\
\text { (kg/plant) }\end{array}$ & $\begin{array}{c}\begin{array}{c}\text { Yield } \\
(\mathrm{kg} / \text { plot})\end{array} \\
\end{array}$ \\
\hline $\begin{array}{l}\text { B. bassiana } \\
\text { B. bassiana }\end{array}$ & $\begin{array}{l}10^{8} \text { conidia } \mathrm{ml}^{-1} \\
10^{10} \text { conidia } \mathrm{ml}^{-1}\end{array}$ & $\begin{array}{c}1.16^{\mathrm{a}, \mathrm{b}, \mathrm{c}}(87.63) \\
0.78^{\mathrm{a}, \mathrm{b}}(91.68)\end{array}$ & $\begin{array}{c}1.01^{\mathrm{b}}(8.67) \\
1.04^{\mathrm{b}}(11.82)\end{array}$ & $\begin{array}{l}40.40 \\
41.60\end{array}$ \\
\hline W. somnifera & $2.5 \%$ & $4.69^{\mathrm{e}}(50.00)$ & $0.99^{\mathrm{a}}(6.48)$ & 39.60 \\
\hline W. somnifera & $5 \%$ & $3.79^{\mathrm{d}, \mathrm{e}}(59.59)$ & $1.01^{\mathrm{b}}(8.67)$ & 40.40 \\
\hline W. somnifera & $7.5 \%$ & $1.44^{\mathrm{b}, \mathrm{c}}(84.64)$ & $1.03^{\mathrm{b}}(10.75)$ & 41.20 \\
\hline G. glabra & $2.5 \%$ & $3.29^{\mathrm{d}, \mathrm{f}}(64.92)$ & $0.99^{\mathrm{a}}(6.48)$ & 39.60 \\
\hline G. glabra & $5 \%$ & $2.32^{\mathrm{c}, \mathrm{f}}(75.26)$ & $0.99^{\mathrm{a}}(6.48)$ & 39.60 \\
\hline G. glabra & $7.5 \%$ & $2.18^{\mathrm{c}}(76.75)$ & $1.01^{\mathrm{b}}(8.67)$ & 40.40 \\
\hline Nimbecidine & $5 \mathrm{ml} / 1$ water & $0.72^{\mathrm{a}, \mathrm{b}}(92.32)$ & $1.06^{\mathrm{b}}(13.97)$ & 42.40 \\
\hline Omite & $0.05 \%$ & $0.12^{\mathrm{a}}(98.72)$ & $1.15(23.65)$ & 46.00 \\
\hline Control & Water spray & 6.78 & $0.93^{\mathrm{a}}$ & 37.20 \\
\hline Control & Untreated & 9.38 & $0.93^{\mathrm{a}}$ & 37.20 \\
\hline C.D. & & 1.08 & 0.07 & \\
\hline $\mathrm{SE}(\mathrm{m})$ & & 0.37 & 0.02 & \\
\hline
\end{tabular}

Values with the same superscript do not differ significantly, Figures in parentheses represent percent reduction in mite population over untreated control and percent increase in yield over untreated control.

population of $T$. urticae which did not differ significantly with $B$. bassiana at $10^{10}$ conidia $\mathrm{ml}^{-1}$ and Nimbecidine (Table 2). Likewise, W. somnifera $(7.5 \%)$ and G. glabra (7.5 and 5\%) were effective in reducing the $T$. urticae population to 84.64 (1.44 mites/ sq. $\mathrm{cm}$ leaf), 76.75 (2.18 mites/ sq. cm leaf) and 75.26 (2.32 mites/ sq. cm leaf) percent after spray as compared to control in which 9.38 mites/ sq. cm leaf were observed. The three treatments did not differ significantly with each other in terms of number of mites recovered after spray. The number of mites in various treatments ranged from 0.12 to 9.38 mites/ sq. cm. leaf. $W$. somnifera at 5 and 2.5 percent reduced the number of mites to 3.79 and 4.69 mites/ sq. cm. leaf as compared to water sprayed (6.78 mites/ sq. cm. leaf) and untreated ( 9.38 mites/ sq. cm. leaf) plots.

Statistical analysis on yield of cucumber (kg/ plant) depicted a significant difference $(C D=0.07, p=0.05)$ among different treatments (Table 2). The highest yield (1.15 kg/ plant) was recorded with Omite treatment while the lowest was obtained in control $(0.93 \mathrm{~kg} /$ plant $) . \quad$ B. bassiana $\left(10^{10}\right.$ conidia $\left.\mathrm{ml}^{-1}\right)$ treatment yielded $1.04 \mathrm{~kg} /$ plant which was statistically in comparison with $B$. bassiana treatment $\left(10^{8}\right.$ conidia $\mathrm{ml}^{-1}$ ) which yielded $1.01 \mathrm{~kg} /$ plant. Nimbecidine treatment led to a higher yield of $1.06 \mathrm{~kg} / \mathrm{plant}$, which was found to be statistically comparable to B. bassiana treatment $\left(10^{10}\right.$ conidia $\left.\mathrm{ml}^{-1}\right)$. Regarding yield, no significant difference was found among $W$. somnifera leaf extract treatment at 5 percent and 7.5 percent and G. glabra stem extract treatment at 7.5 percent. All the three treatments were also found to be statistically insignificant to Nimbecidine. However, the lower concentrations of W. somnifera $(2.5 \%)$ and G. glabra (2.5 and 5\%) were found to be statistically at par with each other.

\section{DISCUSSION}

During the present study an acaricide, Omite $(0.05 \%)$ was evaluated against $T$. urticae which caused high toxicity (98.72\% over untreated control) in field trials after four sprays. B. bassiana treatment showed nonsignificant difference with Omite treatment. Kumar and Singh (2005) reported that after one day of spray, maximum mite mortality $(94.8 \%)$ was in Omite + Dhanuvit 57EC $(0.114+1 \mathrm{ml}$ concentration) followed by Omite 57EC $(0.114 \%)$, phosalone 35EC $(0.07 \%)$ and ethion 50EC $(0.05 \%)$ which caused $88.9,58.8$ and 52.8 percent mortality, respectively on okra. The present results are in agreement with those documented by Geroh (2011) on okra. Higher concentration $\left(0.3 \times 10^{9}\right.$ conidia $\left.\mathrm{ml}^{-1}\right)$ of $B$. bassiana strain ITCC- 4668, 6063, 5549 and 4513 were found to be at par with another standard acaricide, ethion treatments in reducing mite population of $T$. urticae (51.03 to $62.36 \%$ ). Similar findings on low to moderate toxicity of ethion were reported by earlier workers (Rai et al., 1993; Kumar and Singh, 2005) up to three days after spray whereas some reported high toxicity (Mani et al., 2003) against T. urticae.

Acaricidal effect of $W$. somnifera and G. glabra extracts tested at three concentrations $(2.5,5$ and $7.5 \%$ each) against $T$. urticae was recorded in a concentration dependent manner. Under the conditions tested, both the extracts appeared to work best at the 7.5 percent dose, by virtue of higher percent reduction in $T$. urticae population followed by 5 and 2.5 percent concentrations. Scarce literature was available on the effect of $W$. somnifera extract against $T$. urticae. Gulati et al. (2006) reported effectiveness of W. somnifera 
extract at 5 and 10 percent concentrations against $T$. urticae on okra. However, reports are available on the insecticidal action of $W$. somnifera extract. $W$. somnifera was evaluated for its larvicidal property against mature larvae of Tribolium castenum by Arora et al. (2011). Morphological abnormalities and significant mortality was observed in treated larval forms at higher dose levels (10\%). Parkash et al. (2005) studied the antifungal activity of W. somnifera on some phytopathogenic fungi and reported significant inhibition of fungal growth at higher dosages (2500 ppm) as compared to lower dosages (1000, 500 and $100 \mathrm{ppm})$. Likewise, aqueous root extract of $W$. somnifera was found to possess strong antibacterial activity against Staphylococcus aureus (Mehrotra et al., 2011). No report supporting acaricidal action of G. glabra against $T$. urticae was found. However, G. glabra had pronounced effect on the honey bee mite, Tropilaelaps clareae (Hosamani et al., 2006) and brought significant reduction in $T$. clareae in Apis mellifera colonies. Anita (2010) also showed a pronounced effect of $G$. glabra extract against the stored product mite, Tyrophagus putrescentiae. It provided 71.5 to $94.7,78.3$ to 92.3 and 77.2 to 92 percent relative protection against $T$. putrescentiae after 15,30 and 45 days post treatment.

It can be inferred that botanicals viz., W. somnifera and G. glabra extracts did not excel the synthetic acaricide, Omite because they have a tendency to degrade much faster than chemicals when exposed to sunlight, rainfall and other weather parameters. Eventhough the effectiveness of botanicals is not superior to chemicals, they are moderate in their efficacy in reducing the mite population due to myriad modes of action. Considering their eco- friendly and non toxic nature, the botanicals may be recommended for the suppression of mites in perishable goods such as vegetables in alternation with synthetic chemicals. Superiority of the neem product compared to other botanicals may be due to its azadirachtin content, which exhibited high ovicidal, antifeedent and insecticidal growth inhibitory properties resulting in suppression of mite population (Pushpa, 2006). Good amount of phenolics and terpenoids found in botanical extracts constitute biologically active compounds to be used in pest management (Mehrotra et al., 2011).

The present investigation, thus clearly revealed that entomopathogenic fungus, $B$. bassiana is a promising alternative to chemical insecticides against $T$. urticae. Foliar applications of B. bassiana $\left(10^{8}\right.$ and $10^{10}$ conidia $\left.\mathrm{ml}^{-1}\right)$, W. somnifera $(7.5 \%)$ and G. glabra $(7.5 \%)$ extracts are thus recommended for future studies on the management of two spotted spider mite, T. urticae in cucumber.

\section{ACKNOWLEDGEMENTS}

Beauveria bassiana culture (Hyderabad strain) provided by Dr. P.S. Vimala Devi, Directorate of Oilseeds, Hyderabad is duly acknowledged.

\section{REFERENCES}

Anita (2010). Feeding potential of Tyrophagus putrescentiae Schrank (Acari: Acaridae) and its management. M.Sc. Thesis, CCSHAU, Hisar.

Arora, M., Sharma, J., Singh, A. and Negi, R.S. (2011). Larvicidal property of aqueous extracts of Withania somnifera on Tribolium castenum. Indian J. of Fundamental and App. Life Sci., 1(2): 32-36.

Bastos, S., Egewarth, R., Sausen, C., Soares, V. and Prado, L. (2009). Action of plants extracts on oviposition and on mortality of diamondback moth. Ciencia Rural., 39: 551-554.

Chandler, D., Davidson, G., Pell, J.K., Ball, B.V., Shaw, K. and Underland, K.D. (2000). Fungal biocontrol of Acari. Biocontrol Sci. Technol., 10: 357-384.

Clemente, S., Mareggiani, G., Broussalis, A., Martino, V. and Ferraro, G. (2003). Insecticidal effects of Lamiaceae species against stored products insects. Boletín de Sanidad Vegetal. Plagas, 29: 1-8.

Clotuche, G., Mailleux, A.C., Ferna'ndez, A.A., Deneubourg, J.L. and Detrain, C. (2011). The formation of Collective Silk Balls in the Spider Mite Tetranychus urticae Koch. PLoS ONE, 6(4): 1804-1817.

Daoubi, M., Deligeorgopoulou, A., Macias-Sanchez, A. J., Hermamdez-Galan, R., Hitchcock, P.B., Hanson, J.R. and Collado, I.G. (2005). Antifungal activity and biotrans formation of diisophorone by Botrytiscinerea. J. Agric. Food Chem., 53: 6035-6039.

García, R.M., Pérez, P.R., Rodríguez, H.C. and Soto, H.M. (2004). Toxicidad de alcaloides de Eythrina americanaen larvas de mosquito Culex quinquefasciatus. Fitotecnia Mexicana, 27: 297-303.

Geroh, M. (2011). Molecular Characterization of Beauveria bassiana (Balsamo) vuillemin and its bioefficacy against Tetranychus urticae Koch (Acari: Tetranychidae), Ph. D. Thesis, CCS HAU, Hisar.

Gulati, R., Sharma, S.K. and Dhillon, S. (2006). Field efficacy of botanical extracts against Tetranychus urticae Koch (Acarina: Tetranychidae) in okra. In: Internat. Sym. Current Issues Zool. Environ. Sci., DDUGU, Gorakhpur .

Hosamani, R.K., Gulati R., Sharma, S.K. and Kumar, R. (2006). Efficacy of some botanicals against Tropilaelaps clareae in Apis mellifera L. Colonies. Syst. Appl. Acarolo., 12: 99-108.

Kumar, S. and Singh, R.N. (2005). Effect of omite and some other acaricides against the mites, Tetranychus urticae Koch and T. neocaledonicus Andre on okra and brinjal under field conditions in Varanasi, Uttar Pradesh. Pestology, 29(8): 15-19.

Kumar, S.V., Chinniah, C., Muthiah, C. and Sadasakthi, A. (2010). Management of two spotted spider mite Tetranychus urticae Koch a serious pest of brinjal, by integrating biorational methods of pest control. $J$. Biopestic., 3(1): 361-368.

Mani, C., Kumar, S. and Singh, R.N. (2003). Efficacy of acaricides and botanicals against two spotted mite, Tetranychus urticae Koch on okra.Ann. Pl. Protec. Sci., 11(1):153-154.

Mehrotra, V., Mehrotra, S., Kirar, V., Shyam, R., Misra, K., Srivastava, A.K. and Nandi, S.P. (2011). Antioxidant and antimicrobial activities of aqueous extract of Withania somnifera against methicillin-resistant Staphylococcus aureus. J. Microbiol. Biotech. Res., 1 (1): 40-45. 
Migeon, A. (2009). Modelling the potential distribution of the invasive tomato red spider mite, Tetranychus evansi (Acari: Tetranychidae). Exp. Appl. Acarol., 48: 199212.

Parkash, V., Aggarwal, A., Sharma, S., Gupta, S. and Gupta, A. (2005). Antifungal activity of Withania somnifera (L.) Dunal on some phytopathogenic fungi.Bul. Nat. Inst. Eco., 15: 215-218.

Pushpa, V. (2006). Management of coconut perianth mite, Aceria guerreronis Keifer. MSc. Thesis, University of Agricultural Sciences, Dharwad, India.

Rai, A.B., Bhanderi, G.R. and Patel, C.B. (1993). Effectiveness of neem based products (Azadirachtin) against Tetranychus macfarlanei (Tetranychidae) on okra (Abelmoschus esculentus L.) Monech and their safety to predatory mites. Neem Newsl., 10: 26.

Van Leeuwen, T., Vontas, J., Tsagkarakou A., Dermauwa W. and Tirry, L. (2010). Acaricide resistance mechanisms in the two-spotted spider mite Tetranychus urticae and other important Acari: A review. Insect Biochem. and Mol. Biol., 40: 563-572.

Varela, A. and Morales, E. (1996). Characterization of some Beauveria bassiana isolates and their virulence towards the coffee berry borer Hypothenemus hampei. J. Invert. Pathol., 67: 147- 152

Vimala Devi, P.S. (2003). Role of entomopathogenic fungi in insect pest management. In Winter School on new Dimensions in Integrated Pest Management in Major Field Crops, Directorate of Oilseed Research, Rajendranagar, Hyderabad, pp, 149-156. 